\title{
THE ROLE OF THE COMMUNITY MENTAL HEALTH NURSE IN BOTSWANA: THE NEEDS AND PROBLEMS OF CARERS OF. SCHIZOPHRENIC CLIENTS IN THE COMMUNITY.
}

\author{
A Kgosidintsi
}

\section{INTRODUCTION}

The purpose of this study was to identify and describe the role of the psychiatric/community mental health nurse in the context of primary health care in which mental health is an integral part of the general health care system and in a specific socio-economic background. Nine (9) community mental health nurses who graduated from a local training program for community mental health nurses at post basic level, twenty five (25) carers responsible for daily care and welfare of schizophrenic clients from rural, semi-rural, urban and semi-urban areas country wide participated in the study. The study was exploratory and both qualitative and quantitative data was collected using semi structured interviews, unstructured observation and documentary search methods were used. Data analysis for both qualitative and quantitative data was done through simple frequency counts.

Findings indicated that the community mental health nurse's role was mainly technical with three main functions.

- Mental Status Assessments of Clients

- Prescribing Treatment and

- Administration of Treatment through injection and other routes.

Carers complained of inadequate care and support from nurses, social and economical burdens of caring for clients in the community and an expressed need for periodic re-admission of chronic clients to hospital and rehabilitation services for discharged patients in the community.

The study concluded that, the role of the community mental health nurse is more than just the technical activities identified. It is highly dependent on, the availability of resources, characteristics of clients and care givers in the community and the nurses professional preparation which is vital in providing him/her with the confidence to objectively evaluate changes occurring around him/her and make necessary judgements and adjustments in her role.
The community approach to mental health in Botswana began in 1977 commencing with a pilot project in which an outpatient clinic was set up in one of the health centres. A psychiatric nurse was assigned to nun the clinic (M.O.H 1984). When the pilot project proved successful, five other psychiatric nurses were assigned to establish psychiatric units in strategically located hospitals and health centres around the country. An out patient was also established in the country's only mental hospital.

The program was built around the existing group of psychiatric nurses and the only psychiatrist in the country. All the nurses and the psychiatrist were trained outside the country in institutionally based training programs. No additional staff were available.

\section{THE COMMUNITY BASED \\ MENTAL HEALTH CARE MOVEMENT}

The community based mental health care movement sought to enable most patients identified as suffering from psychiatric disorders to receive care and treatment within their communities, to increase the availability of services and to initiate preventive activities.

The thrust of the program was to make the services community based as opposed to the custodial care that had been practised since 1938. Community resources such as the extended family, clergymen, village elders, both governmental and non-governmental organizations were mobilized to participate in the care of the mentally ill in the community and refer to the psychiarric personnel those that became unmanageable in the community. (Ben-Tovim 1987).

\section{STATEMENT OF THE PROBLEM}

As accessibility of the psychiatric services increased, so did the utilization of services. Figures from the registers kept in all the psychiatric units showed that whilst the referrals increased only modestly, the number of repeat consultations increased six fold. (Bentovim 1987 p. 192). Although coverage of mental health services had improved since the community based psychiatric service was launched, its quality was hard to measure. A visiting W.H.O consultant remarked that curative skills and skills in interviewing, communication, counselling, behaviour and relaxation therapies were lacking among both the psychiatric educators and nurses running the psychiatric units. (German 1984).

The post basic mental health nursing outcome objectives were spelt out as follows:

- To prepare a nurse to render preventive promotive curative and rehabilitative services to communities in his/her catchment area with minimum time spent in the unit.

- Supervise and teach health workers participating in the delivery of mental health care.

- Support and partake in community activities and coordinate all mental health projects in collaboration with the psychiatrist in charge.

Literature indicates that the role of the psychiatric/community mental health nurse is influenced by a number of factors such as:-

- The socio-cultural and economic situation where they work.

- The authoritarian system of care designed to show that nursing functions are a response to physicians' judgements and orders.

- Self confidence built on the strong educational background which is vital to allow the nurse to evaluate changes around her and make necessary judgements and adjustments to function as an independent practitioner with minimum reference to the psychiatrist.

- The attitudes that prevail among colleagues and other health professions and those of the clients and carers.

The psychotherapeutic and medical treatment skills of the community mental nurse had been questioned (Wankiri 1984 German 1986). The educational preparation had been found to 
be appropriate for hospital oriented personnel and a recommendation was made to emphasise skills pertinent to the nurses work as described in the curriculum to allow him/her to function autonomously in the community based program.

The prevailing attitudes among the community mental health nurses, their colleagues, and medical professionals which were developed from institutionally based training based on the disease model. This influenced the nurse in psychiatric training towards a curative model of care.

The communities had been medicalised over the years and made to believe that mental illness could only be treated in institutions and they demanded a curative community service.

The socio-economic and clinical characteristics of carers and clients in the community largely influenced the role of the community mental health nurse who responded to community's needs in planning nursing interventions.

Sociological literature suggests that, to conceive of mental disorder as illness, implies that the sick person has a special stanis in relation to others. The status of being 'sick' absolves the mental patient of most of his social responsibilities and entitles him to the help of his fellows. Literature also notes that the capacity of the family to support a dependent member fluctuates with the progress of its cycle of development (Wilson H.S. 1989).

The effect of urbanization in the family structure was characterised by migration of the productive age group to urban areas to seek gainful employment thus reducing the extended family structure. This in turn reduced the family's ability to care for the sick member and its capacity to maintain a mentally ill dependent adult.

\section{RESEARCH QUESTIONS}

- What are the role activities of the community mental health nurse in the psychiatric unit, mobile clinics and during home visits?

- How does he/she meet the program objectives to carry out health promotion and preventive services?

- What therapeutic activities are carried out by the community mental health nurses and to whom do they refer clients when in doubt?

- What are the problems faced by the carers of clients diagnosed as schizophrenic?

- What do carers want as help from the nurses?

\section{METHOD}

\section{Sample:}

The nine community mental health nurses who graduated from a local training program with a similar educational background

Carers were defined as anyone providing daily care for a client diagnosed as schizophrenic.

Carers were identified from the clinic registers and followed to their homes with the help of the community mental health nurse.

Carers must have been living with the client for over eight weeks prior to the study and have been visited at least once by the nurse during this period. The actual period of care ranged from a year to several years.

At least three families from each area where the community mental health nurse was based.

\section{Data Collection:}

Face to face semi-structured interviews of unlimited time depending on the willingness of the participant to respond to questions were conducted for both the nurses and carers.

Non-participant observations were made of nurses activities for the rest of the day and relevant nursing records including work plans and nursing notes were studied. Observation of interaction between the nurse and carers was observed during home visits.

\section{Data Analysis:}

Interviews were tape recorded. Analysis basic themes shared by study sample and simple frequency counts were made.

\section{FINDINGS}

The role activities of the community mental health/psychiatric nurse. For the purpose of the study, community mental health/psychiatric nursing was considered a component of the whole field of nursing. Entry qualifications to post basic training require that one be a general nurse. Activities were categorised as follows in order of highest ranking

1. Technical and regulatory activities

Mental status assessments

Prescribing treatment including

psychotropic drugs

Administering treatment

Applying dressings

Tracing client's whereabouts

Escorting clients to hospital

2. Health education on various topics

3. Interpersonal procedures which included methods of approach used when interacting with the clients and their families. These included counselling giving instructions or information and offering practical help and referral to others.

4. Basic nursing skills such as hygienid/nutrition care were ranked lowest. Nurses reported that such duties were left to families.

\section{NEEDS AND PROBLEMS OF CARERS}

Characteristics of carers and clients indicate that; more than $50 \%$ were above the age of 50 , single and unemployed. They were unskilled and had only gone up to lower primary school. The following are examples of responses to open ended questions put to carers:

- Have you experienced any problems living with the patient?

- What is your biggest problem in living with the patient?

- Who else can help in caring for the patient?

- What do you think can be done?

- How do you feel about the care you have received from the nurses?

Twenty five carers participated in the study, three each from seven of the areas in which the community psychiatric nurses are based and two each from the other two areas. The other two carers from these areas dropped out of the study on the date of appointment. One of the carers had to leave the village for some other important matters elsewhere while the second was not available at her home for the interview.

Responses were summarised as follows:

1. Have you experienced problems living with the patient?

a) An unemployed mother in her mid $40 \mathrm{~s}$ with five children, two still at primary level. Client is the eldest, has been admitted twice to hospital since the illness started two years ago.

"Yes, I never know what he is up to. He is never home. I am always worried that he might get into trouble. When he is home, he is aggressive and demanding. I am always scared that he might attack me at any time".

b) A lady in her late 50s lives with two clients, both her children. None of them is working, they rely on money sent to them by the elder sister who is a domestic worker in town with her own two young children.

"Yes, illness in the family is a problem and this one is not an exception".

c) An unmarried unemployed mother of four survives on money from selling firewood. Client is in early 20 s with one daughter.

"I've got a lot of problems. I am unemployed, I've no one to look for help. She 
will not listen to me talking to her. She moves around with men and yet does not want to use family planning methods. She does not even help me fetch firewood to earn our living, she just roams around the village".

d) A lady in her early 50s lives with her brother and the client, who is the youngest brother.

"He does not bother anybody as long as he has had something to eat, he keeps himself busy, washes his own clothes. The onty problem is that he does not talk to anyone of us, he talks and laughs all alone, he keeps to himself. When his illness starts, he becomes destructive and verbally aggressive. We don't know how we can get him to socialize with the family or even neighbours".

e) An elderly man, living with elderly wife, the client and a daughter with two children, who is also epileptic and the youngest son, who is mentally handicapped. The couple are registered with the Social Welfare as destitute, living in a two-roomed flat. The couple shares one room with the client as a bedroom, while the daughter and the youngest brother share the other room with the young children.

"He is unpredictable, he has bouts of violence which are unprovoked, which are usually directed towards his father in most cases. He refuses to take treatment from anyone else but his mother. He will not even bath himself or wash his own clothes. He spends the day lying under a tree smoking tobacco which he demands from his mother. He sometimes undress and moves around naked in front of the young children. He is just unmanageable and I wish you could take him away with you, at least for a few months".

2. What is your biggest problem?

a) Mother married, husband away from home, works in the mines and comes home only once at the end of the month

"He is my biggest problem. He is dependent on me for everything, even his hygienic need. If I don't force him to bath he never does. I can't even leave him here alone to visit. I would find him either having destroyed my property or having wondered away in search of food.

b) Widowed mother of six. Works as a domestic helper. Lives with two clients, her own brother and her son. Other children are at school. They live in a two-roomed flat.

"Violence and alcohol abuse is the main problem with the two of them. They can't even get jobs to help me feed them. When they have money from cas- ual jobs, which they often get, they spend it all on alcohol and come home to demand food I just can't cope with them".

c) A grandmother, who lives with her daughter who is schizophrenic and the daughter's son who also is schizophrenic. She is supported by her other sons who are working. They live in a comfortable home. Her eldest son is handicapped but is engaged in pottery-making, earning a living from it.

"My daughter is not violent. Although I have to supervise her hygiene, she is not a problem. Her son is my biggest worry that will send me to my grave. Sometimes I wish he could be knocked down by a car or train then we shall grieve only once but it will be over. His uncles cannot afford to maintain us and him. He can't get a job because of his violence. He abuses drugs and alcohol and has destroyed my property. I am poor because of him".

d) A father with four young children, married and lives with brother who is schizophrenic. He works in town but comes home at week-ends to see his family.

"I cannot allow him into my house. He is destructive, he is a big man who should be having his own family and earning his own living. I cannot put my family's lives at risk by allowing him into my house. My wife gives him food. He refuses to take treatment so he can. not be trusted He sleeps outside the house. I don't know where he goes to during bad weather".

e) An elderly woman, over sixty years old, lives along with the client, who is a grandson. His mother lives in Zimbabwe where she is married and never comes home. Client's sister is married with her own family.

"I live in fear that one day he will just kill me. He abuses alcohol and drugs, refuses treatment. He is never home during the day. When he comes back at night he fights me, demanding food and money. The sister has stopped coming here. She says her husband stops her from giving us money or anything because he thinks the client is being irre. sponsible deliberately"

3. Respondents were asked to say what would help them most.

a) "I really do not know what might be of help. I've been to traditional healers for help and the hospitals do not seem to be helpful at all"

b) The elderly woman living with two clients, her daughter and her daughter's son, who are both schizophrenic, responded by saying:

"I don't think anything or anybody can help resolve my problem. Friends have fled, relatives also keep away, they only sympathise with me but are no practical help. The nurses will not even take them away for at least one or two months while I attend to my fields. The police at least respond to my call when there is violence caused by them".

Some carers suggest that:

"It would probably help if they were admitted periodically to give us a break and time to go to the fields to plough. We have been completely cut off from community activities and those activities we us ed to eam our living by".

4. Carers were asked if they thought that information on the dynamics of the illness and management could help:

"I really do not know because the nurses always tell us that the tablets can help but they (the clients) refuse to take them. I don't see how information without help from the nurses can help".

"Maybe information can help if we are told whom to contact in times of crisis or when the patient refuses to take treatment. I feel helpless when they refuse treatment or when they become aggres. sive".

5. Who else can help in caring for the client?

"Nobody helps in any way. I am always alone when my son's illness starts. The police and the nurses are the only source of help I have during crisis".

"Relatives are now scattered all over the country in jobs. Those left behind are helpless. They need to be cared for too. I used to inform them but I've stopped because they have not been helpful at all".

"Social workers have abandoned us, they say my sons who are working should help us with food and clothing but they also have their families to care for and they are not eaming much. At the clinic food is only given to the under-nourished under-fives and patients with tuberculosis. They say he (the client) does not qualify for ration food".

"I am an active church member. I've even joined the women's group. When my son's illness started, I reported to the priest and the women's group. None of them has set foot in my home to at least pray for me and my son. I've decided to leave the church". 
"Traditional healers have begun charging high fees for their services. I've run out of money. I cannot afford it but maybe my daughter would get better".

\section{What would help you most?}

Some carers said they did not know what other help was available besides the hospital and the police.

"I wish nurses could supervise treatment for them in the community because they refuse to take it from us and because they are adults, we cannot force them to take it against their will".

"I wish they could be admitted to hospital periodically to relieve the relatives of the burden of caring for them and give them time to find ways of earning a living and participate in community activities. When they are around, we are completely solated from community life".

"I wish he could be admitted for life in hospital. It would be better for everybody".

\section{What do you think can be done?}

"I don't know because I don't know what services are available for people with mental illness".

"I think it would help of the public could be taught to help the mentally ill and avoid giving them alcohol and dagga"

"I think the mentally ill could benefit from rehabilitation schools. The carers would also find some relief in caring for them and knowing that the clients are doing something useful".

8. How do you feel about the care you have received from nurses?

"I have no complaints about the help I have received from nurses. They have always come to my rescue when my son's illness starts"

"I don't know because I don't know what else the nurse should do besides giving treatment".

"I think the care they give us is inadequate. Maybe they could teach us about mental illness, supervise daily treatment and visit the patients in their homes to rehabilitate them".

\section{Discussion of Findings}

The study sought to identify and describe the role of the Community Mental Health Nurse in Botswana.

The findings have indicated the role of the Community Mental Health Nurse is indeed influenced by the setting where work takes place, his/her own perception of what her role is, the characteristics of those who receive care.

It could be inferred from the findings that the large catchment area which the only Psychiatric Mental Health Nurse had to cover acted as a limiting factor with regard to the variety of services she provided to the clients. It is also possible that her professional preparation could have had an influence. The curriculum she had gone through did not prepare her for a community based program.

The Nurses have to be sure of what nursing is to be able to manage the factors influencing their practice.

Although no conclusions can be drawn from these findings, they raise a lot of questions to be researched upon.

\section{Needs and Problems of Carers.}

The socio-economic characteristics of clients and carers investigated indicated that most were unemployed, with no regular source of income. Most of the clients fell within the productive age, where they are expected to be earning their own living and having families. Most were male and unmarried and had to be supported and maintained they their families.

The views of carers varied over the role of the client. Some acknowledged that the client was ill and afforded him the sick person's status and exempted him from responsibility of finding a job or even carrying out normal social duties in the home. Others felt that, because of the economic pressures that the family was facing, the client, as long as he was out of hospital, would not be excused from taking up paid jobs to provide the family with income. Families who felt this was resented the clients' idle behaviour, to the point of refusing them access to household facilities, including shelter.

The same group of carers felt strongly that clients need rehabilitation to be able to be independent and that periodic admissions to hospital to relieve them of the burden of caring for the clients was essential.

Rehabilitation, as part of tertiary care, has been described as an expensive project, as it calls for provision of resources to cater for the varying needs of clients. In Botswana, rehabilitation services have mostly been funded by non-governmental organizations and donor agencies from foreign aid. They have concentrated on the physical and mentally handicapped specifically. No project exists on record for the mentally ill specifically for rehabilitation of those discharged into the community.

The Occupational Health Unit in the only Mental Hospital is very small. It provides limited services for just a few, so that preparation for discharge is basically nil for most, especially the chronic patients.

The question of social welfare or maintenance of clients in the community is a difficult one.
Unemployed families have to rely on one member, even if it is an extended family member who is working for their support. Mental patients are not automatically eligible for social welfare, unless it can be proved that "The client if without assets (resources such as cattle, other livestock, land, cash) cannot plough due to ill health or handicaps, close family members cannot/will not help." (National Policy on Destitutes, 1980).

Although the policy is under review because of changes in the family structure and national economic trends, the situation will take a long time to change for the mentally ill because of the stigma associated with the illness, and views held by some that the mentally ill in the community are fit to hold jobs and should make efforts to find jobs.

Legislation on admission to hospital, as stated in the Mental Disorders Act, 1979, in the laws of Botswana restricts admission to hospital to a person who, according to medical opinion, is:

"In consequence of mental disorder. defect of reason or mind ... is incapable of managing himself or his affairs ... or a danger to himself or other, or is unable to conform with the ordinary us. ages of the society in which he lives... or requires supervision or treatment or control ... will benefit from admission to hospital".

Although the Act is under review, the draft of the new Act, although not yet approved, makes no provision for periodic readmissions or chronic clients.

The above limitations of policies and legislation influences the role of the community mental health nurse in the direction of finding alternative solutions to the needs of carers.

\section{CONCLUSION}

The role of the community mental health nurse is very diverse. It is directed mainly by the country's legislation and policies of health, social welfare and availability of resources. It requires money to establish and maintain programmes for promotion of mental health, preservation of health and rehabilitation of the chronically ill. Manpower has to be adequate to run the programmes, both skilled and unskilled, with the ability to collaborate with other disciplines or agencies to achieve health goals for community members. The community mental health nurse requires sound knowledge and skills and a positive attitude towards clients and their carers. The absence of the above requirements would make the realisation of goals for community care, that is, of benefit to the consumers, just a myth.

Lack of transport has been mentioned as a problem throughout the report. 
The needs to support carers has emerged as a discretionary activity by the nurse. It is concluded here that it should be seen as part of the main role of the nurse, in which skills, such as interpersonal procedures as described in the study, can be used. The family requires all services offered to the clients to promote their mental health and prevent mental illness by alleviating emotional and physical burdens from caring for the client.

Lack of rehabilitation services has been noted in the study to make the nurse helpless in providing service to both carers and clients. The need for relief of this burden was the main thing expressed by carers.

The provision of the services mentioned above could lead to definition of what could be said to be professional community psychiatric mental health nursing. What has been observed in the study and literature reviewed is that community psychiatric mental health nursing is determined by what has to be done for the mentally ill, based on resources available and as dictated by others with whom the nurses are working.

There is a need to develop some structure for both individual and community care of the mentally ill, with both short and long term objectives as a means of directing nursing activities in the community. Such structure and objectives could be used as ways of directing other community resources involved in the care of the mentally ill and their families, under the supervision of the community mental health nurse. The structure might avoid haphazard functions which might be difficult to evaluate and control.

Information for carers in the direction of influencing self care appears to be inadequate. The involvement of low cost resources, such as volunteers and village health committees, may alleviate the manpower shortage in informing and educating the carers and other community members on the care of the mentally ill.

Provision of accommodation for the chronically ill without shelter could be considered as a matter of urgent need, to avoid patients becoming involved in serious crimes because of lack of proper monitoring of their medication.

Support groups in the community for families with schizophrenic clients living in the community are an essential resource in dealing with the emotional burden of caring for the mentally ill. Community mental health nurse could act as key persons in influencing community members to establish such support groups.

Constant evaluation of the programme by authorities, clients and carers would give the real picture of the success of failure of a community programme for the mentally ill, unlike evaluation of prescribed objectives.

The role of the community mental health nurse is not static, but changes constantly, depending on the factors identified above, including the characteristics of carers and clients, who are the consumer of care.

\section{REFERENCES}

Ben-Tovim, D. (1987): Mental Health and Primary Health Care in Botswana. London. Tavistock. p. 27

$$
\text { i }
$$

German, A. (1984): A Consultancy Report on Training of Mental Health Personne and General Health Workers. Geneva World Health Organization.

Wankiriri, V.B. (1984): External Examiners' Report: Community Mental Health Nursing, Gaborone. Botswana Nursing Council/National Health Institute

Wilson, H.S. (1989): Family Care giving for a Relative with Alzheimer's Dementia: Coping with Negative Choices. Nursing Research 38 No. 2 p. 94 - 97.

Institute of Development Management -
Gaborone Botswana 